\title{
Badania mikrotermometryczne i ramanowskie inkluzji $w$ minerałach w rejonie Rabego (Karpaty) - praktyka eksperymentalna
}

\author{
Katarzyna Jarmołowicz-Szulc ${ }^{1}$, Tomasz Toboła ${ }^{2}$
}

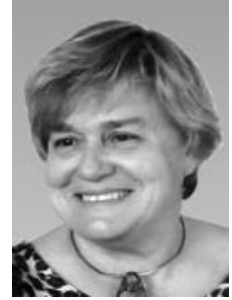

K. Jarmołowicz-Szulc

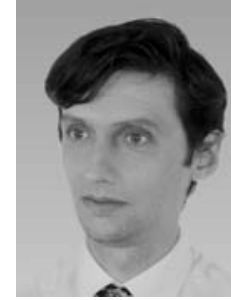

T. Toboła

Microthermometric and Raman spectra studies in minerals in the Rabe vicinity (Carpathians) - an experimental practice. Prz. Geol., 69: 361-364; doi: 10.7306/2021.18

A b s $\operatorname{tr}$ a c t. Fluid and solid inclusions were analyzed in minerals of Carpathian rock samples from the Rabe vicinity by means of microthermometry and Raman spectrometry. Fluid inclusions are present in calcite and quartz that often co-occur with organic matter in different spatial relationships. In case of the studied Ra 5 sample they fill a cavern in the mélange zone in the Carpathian flysch. The temperatures obtained from the combined research (FI 178.9$186^{\circ} \mathrm{C}$; Raman $178-205^{\circ} \mathrm{C}$ ) give an insight into the geological history of that fragment of the Carpathians.

Keywords: fluid inclusions, solid inclusions, Carpathians

Badania inkluzji fluidalnych w minerałach są przeprowadzane w celu diagnozy wypełniających je fluidów, które mogą zawierać wodę, solankę i/lub węglowodory czy gazy (Roedder, 1984). Charakterystyka i badania wrostków gazowo-ciekłych pod kątem relacji temperatura-ciśnienieobjętość-skład dla poszczególnych inkluzji dostarczają wielu ważnych informacji dotyczących historii termicznej basenu oraz potencjalnej migracji węglowodorów (np. Roedder, 1984; Dutkiewicz i in., 2003). Badania ramanowskie pozwalają na analizę zarówno inkluzji ciekło-gazowych, jak i wrostków stałych (Burke, 2001; Frezzotti i in., 2012).W ostatnich latach badania ramanowskie substancji organicznej zaczęto także stosować w celu wykorzystania jej jako geotermometru (m.in. Beyssac i in., 2003; Kouketsu i in., 2014; Toboła, Botor, 2020).

\section{OBSZAR BADAŃ}

Badane próbki pochodzą z rejonu miejscowości Rabe w Karpatach. Próbki pobrano ze ścian potoku Rabskiego, gdzie w ciemnych, złupkowaconych skałach występują większe i mniejsze bloki o charakterze block in matrix, klasty i soczewki (Jankowski, Jarmołowicz-Szulc, 2009). Fragmenty klastów mają różne rozmiary - od kilkudziesięciu centymetrów do kilku metrów. Wykazują zdeformowanie kanciaste lub zaokrąglone, są spękane. Te spękania są wypełnione mineralizacją, która stanowi przedmiot analiz petrograficzno-mineralogiczno-geochemicznych.

W zboczach doliny potoku Rabskiego znajdują się żyły i żyłki kalcytowe $\mathrm{z}$ bituminami, kalcytowe $\mathrm{z}$ cynobrem (Karwowski, inf. ustna) oraz wystąpienia bituminów z diamentami marmaroskimi. Uwarunkowania geologiczne obszaru są przedstawione w literaturze (np. Jankowski, Jarmołowicz-Szulc, 2009). Wypełnienie kawern i/lub szczelin stanowią węglany (kalcyt, patrz: wyniki analizy ramanowskiej), kwarc i substancja organiczna (por. Dudok, Jarmołowicz-Szulc, 2000; Jarmołowicz-Szulc i in., 2012) - ryc. $1 \mathrm{~A}$.

\section{METODYKA BADAŃ}

Prace badawcze pod kątem inkluzji fluidalnych zamkniętych w minerałach (kwarc, kalcyt) prowadzono wg przyjętego wcześniej, zmodyfikowanego schematu (Jarmołowicz-Szulc, 1999). Połączono je z badaniami widma Ramana (Burke, 2001; Frezzotti i in., 2012) w celu uzyskania szerszej informacji co do składu i charakteru chemicznego wrostków ciekło-gazowych i stałych.

Badania przeprowadzano mikroskopowo w dwustronnie polerowanych płytkach (Goldstein, Reynolds, 1994). Interpretację asocjacji inkluzji fluidalnych oparto na kryteriach Roeddera (1984) oraz weryfikacji Goldsteina (2001), natomiast analizę substancji organicznej przeprowadzono na podstawie procedury Kouketsu i in. (2014).

Badania charakteru fluidów zamkniętych w inkluzjach wykonywano z użyciem aparatury zamrażająco-grzewczej firmy Linkam (zakres temperatur od $23-29^{\circ} \mathrm{C}$ do $250^{\circ} \mathrm{C}$ i do $-70^{\circ} \mathrm{C}$ dla inkluzji wodnych) oraz zestawu fluorescencyjnego Nikon (nadfiolet i światło niebieskie) na mikroskopie Nikon Eclipse. W przypadku potencjalnych inkluzji węglowodorów lekkich zamrażanie prowadzono do $-182^{\circ} \mathrm{C}$. Do obliczania izochor, zasolenia i innych parametrów posłużono się programem FLINCOR (Brown, 1989).

Badania ramanowskie zostały wykonane za pomoca aparatury Thermo Scientific ${ }^{\text {TM}} \mathrm{DXR}^{\mathrm{TM}}$ wyposażonej w laser Nd-YAG o długości fali świetlnej 532 nm. Szczegółowe parametry pomiarów przedstawiono w pracy Toboły (2018). W przypadku analizy inkluzji substancji organicznej zastosowana moc lasera wynosiła 1-2 $\mathrm{mW}$, natomiast dla inkluzji fluidalnych i stałych $-5 \mathrm{~mW}$.

\section{WYNIKI BADAŃ INKLUZJI FLUIDALNYCH I WROSTKÓW STAŁYCH}

Do bieżących badań inkluzji wykonano 6 preparatów dwustronnie polerowanych (grubość do $250 \mu \mathrm{m}$ ). Badania ramanowskie prowadzono na tych samych próbkach. Dla poszczególnych inkluzji typu solankowego i ich asocjacji

\footnotetext{
${ }^{1}$ Państwowy Instytut Geologiczny - Państwowy Instytut Badawczy, ul. Rakowiecka 4, 00-975 Warszawa; kjar@pgi.gov.pl

${ }^{2}$ AGH Akademia Górniczo-Hutnicza, Wydział Geologii, Geofizyki i Ochrony Środowiska, al. Mickiewicza 30, 30-059 Kraków; tobolatomasz@agh.edu.pl
} 
(FIA) uzyskano wartości temperaturowe charakteryzujące poszczególne układy chemiczne, a w przypadku inkluzji węglowodorowych - zmierzono wartości temperatury homogenizacji $\left(\mathrm{T}_{\mathrm{h}}\right)-$ tab. 1 .

Badaniami objęto minerały (kwarc, kalcyt) oraz skupienia bituminów (ryc. 1). W węglanie występują niezbyt liczne i przeważnie słabo widoczne, rozproszone inkluzje fluidalne (FI). Ich obserwacja jest utrudniona ze względu na dużą dwójłomność kryształów. Inkluzje niekiedy wykazują fluorescencję, na ogół brak jest wzbudzenia. Inkluzje w kwarcu w zrostach z węglanem nie wykazują świecenia, natomiast w kryształach typu diamentów marmaroskich zaobserwowano fluorescencję.

Inkluzje (fluidalne i stałe) w przebadanych skałach rejonu Rabego są dość liczne. Ich charakter, wielkość i fazowość są zróżnicowane. Inkluzje fluidalne w kwarcu i węglanie są na ogół małe o wielkości 1-2 $\mu \mathrm{m}$, czasem ich rozmiary sięgają $4 \mu \mathrm{m}$. W temperaturze pokojowej, inkluzje mają na ogół dwie lub jedną fazę, rzadko są trójfazowe. Co charakterystyczne, inkluzje są często porozciagane i porozrywane. Badania luminescencji inkluzji wykazały występowanie nielicznych grup świecących w barwach biało-niebieskich oraz ogólny brak świecenia (ryc. 1). Oddzielną grupę inkluzji stanowią wrostki o charakterze stałym (bituminy). Nie wykazują luminescencji w świetle lampy kwarcowej (nadfiolet). W badanych minerałach występują także inkluzje zawierające gaz. Tworzą one zarówno oddzielnie skupienia (FIA - fluid inclusion assemblages, sensu: Goldstein i Reynolds, 1994) w obrębie spękań oraz szczelin, jak i formy indywidualne.

Uzyskano następujące wartości charakterystyczne dla poszczególnych grup niefluoryzujących inkluzji, a wskazujące na rodzaj wypełnienia wrostków typu AQFI i HCFI:
- dla węglanu - temperatura homogenizacji $\mathrm{T}_{\mathrm{h}}=155,7-$ $180,0^{\circ} \mathrm{C}, \mathrm{T}_{\mathrm{e}}<-33^{\circ} \mathrm{C}, \mathrm{T}_{\mathrm{m}}$ od $-5,8$ do $-6,6^{\circ} \mathrm{C}$;

- dla kwarcu - temperatura homogenizacji $\mathrm{Th}=178,9$ $180,0^{\circ} \mathrm{C}, \mathrm{T}_{\mathrm{e}}$ ok. $-23,3^{\circ} \mathrm{C}, \mathrm{T}_{\mathrm{m}}=-6,12^{\circ} \mathrm{C}$ (tab. 1$)$.

Jednofazowe, ciemne inkluzje wymrażane do temperatury ciekłego azotu generowały pęcherz, którego homogenizacja nastąpiła $\mathrm{w}$ temperaturze $\mathrm{T}_{\mathrm{h}}=-82,6^{\circ} \mathrm{C}$. W trakcie zamrażania zaobserwowano także wydzielenie fazy w pęcherzyku w obrębie inkluzji dwufazowej w kwarcu. Homogenizacja faz w pęcherzyku inkluzji nastapiła w temperaturze $11,2^{\circ} \mathrm{C}$.

\section{DYSKUSJA WYNIKÓW}

Większość dwufazowych inkluzji fluidalnych ma charakter wypełnień wodnych/solankowych (AQFI), o zróżnicowanym kształcie - od sferycznego poprzez nieregularny do zbliżonego kształtem do formy kryształu. Pęcherzyki gazowe wypełniają 10-40\% objętości inkluzji i niejednokrotnie są ruchome w temperaturze pokojowej. Niewielka część inkluzji wykazuje wzbudzenie w barwach biało-niebieskich. Są to na ogół inkluzje o charakterze wtórnym (ryc. 1B). Ich fluorescencja wskazuje na wypełnienie wyższymi węglowodorami (ropa naftowa - por. Jarmołowicz-Szulc i in., 2012; Ping i in., 2020). W minerałach (kwarc) występują inkluzje jednofazowe i, jak to wynika z badań mikrotermometrycznych i ramanowskich, są one wypełnione metanem. W fazie wodnej pęcherz niekiedy jest zawiera dwutlenek węgla. Gęstość tego fluidu wynosi $0,851 \mathrm{~g} / \mathrm{cm}^{3}$ (tab. 1). Bieżące wyniki są zgodne z wcześniejszymi oznaczeniami prezentowanymi w literaturze (Dudok, Jarmołowicz-Szulc, 2000; Jarmołowicz-Szulc i in., 2012).

Analiza ramanowska inkluzji w węglanie wykazała obecność piku kalcytu, definiując jednocześnie rodzaj mi-

Tab. 1. Wyniki badań mikrotermometrycznych inkluzji fluidalnych w węglanie i kwarcu Table 1. Microthermometric results for fluid inclusions in carbonate and quartz

\begin{tabular}{|c|c|c|c|c|c|c|}
\hline $\begin{array}{c}\text { Mineral / } \\
\text { charakter FIA } \\
\text { Mineral / } \\
\text { FIA character }\end{array}$ & $\begin{array}{l}\text { Temperatura } \\
\text { eutektyku } \\
\text { Eutectic } \\
\text { temperature } \\
\left(\mathrm{T}_{\mathrm{e}}\right) \\
\end{array}$ & $\begin{array}{l}\text { Temperatura } \\
\text { topnienia } \\
\text { Ice melting } \\
\text { temperature } \\
\left(\mathrm{T}_{\mathrm{m}}\right) \\
\end{array}$ & $\begin{array}{c}\text { Temperatura } \\
\text { homogenizacji } \\
\text { Homogenization } \\
\text { temperature } \\
\left(\mathrm{T}_{\mathrm{h}}\right)\end{array}$ & \begin{tabular}{|} 
Zasolenie fluidu* \\
[\%wag. ekw. NaCl] \\
Fluid salinity \\
[wt \% $\mathrm{NaCl}$ eq.)
\end{tabular} & $\begin{array}{l}\text { Gęstość* } \\
\text { Density * } \\
{\left[\mathrm{g} / \mathrm{cm}^{3}\right]}\end{array}$ & $\begin{array}{c}\text { Rodzaj FI / Fluid } \\
\text { FI type / Fluid }\end{array}$ \\
\hline $\begin{array}{l}\text { Weglan / dwufazowe } \\
\text { (brak luminescencji) } \\
\text { Carbonate/ two-phase } \\
\text { FI (no fluorescence) } \\
\mathrm{N}=20\end{array}$ & $-33,3$ & $-5,8$ & 155,7 & 8,92 & 0,77 & $\begin{array}{c}\text { AQFI / solanka } \\
\text { brine }\end{array}$ \\
\hline $\begin{array}{l}\text { Weglan / dwufazowe } \\
\text { (brak luminescencji) } \\
\text { Carbonate/ two-phase } \\
\text { FI (no luminescence) } \\
\mathrm{N}=30\end{array}$ & $-47,0$ & $-6,6$ & 180,1 & 9,97 & 0,96 & $\begin{array}{c}\text { AQFI / solanka } \\
\text { brine }\end{array}$ \\
\hline $\begin{array}{l}\text { Kwarc/ dwufazowe } \\
\text { (brak luminescencji) } \\
\text { Quartz / two-phase FI } \\
\text { (no luminescence) } \\
\mathrm{N}=25\end{array}$ & $-23,5$ & $-4,3$ & 178,9 & 6,18 & 0,94 & $\begin{array}{c}\text { AQFI / solanka } \\
\text { brine }\end{array}$ \\
\hline $\begin{array}{l}\text { Kwarc/ dwufazowe } \\
\text { (brak luminescencji) } \\
\text { Quartz / two-phase FI } \\
\text { (no luminescence) } \\
\mathrm{N}=5\end{array}$ & $-23,5$ & n.d. & $\begin{array}{r}180,0 \\
11,4\end{array}$ & n.d. & n.d. & $\begin{array}{l}\text { AQFI / solanka } \\
\text { z CO} 2 \\
\text { brine with } \mathrm{CO}_{2}\end{array}$ \\
\hline $\begin{array}{l}\text { Kwarc/ jednofazowe, } \\
\text { ciemne, wydłużone } \\
\text { (brak świecenia) } \\
\text { Quartz / one-phase FI, } \\
\text { dark, elongated (no } \\
\text { luminescence) } \\
\mathrm{N}=20\end{array}$ & - & - & $-82,6$ & - & 0,172 & $\begin{array}{l}\mathrm{HCFI} / \text { metan } \\
\text { methane }\end{array}$ \\
\hline
\end{tabular}

*Przeliczenia Flincor wg Browna (1989). N - liczba inkluzji w nagromadzeniu; n.d. - nie określono

*Calculations using Flincor program after Brown (1989). N-number of inclusions in FIA 

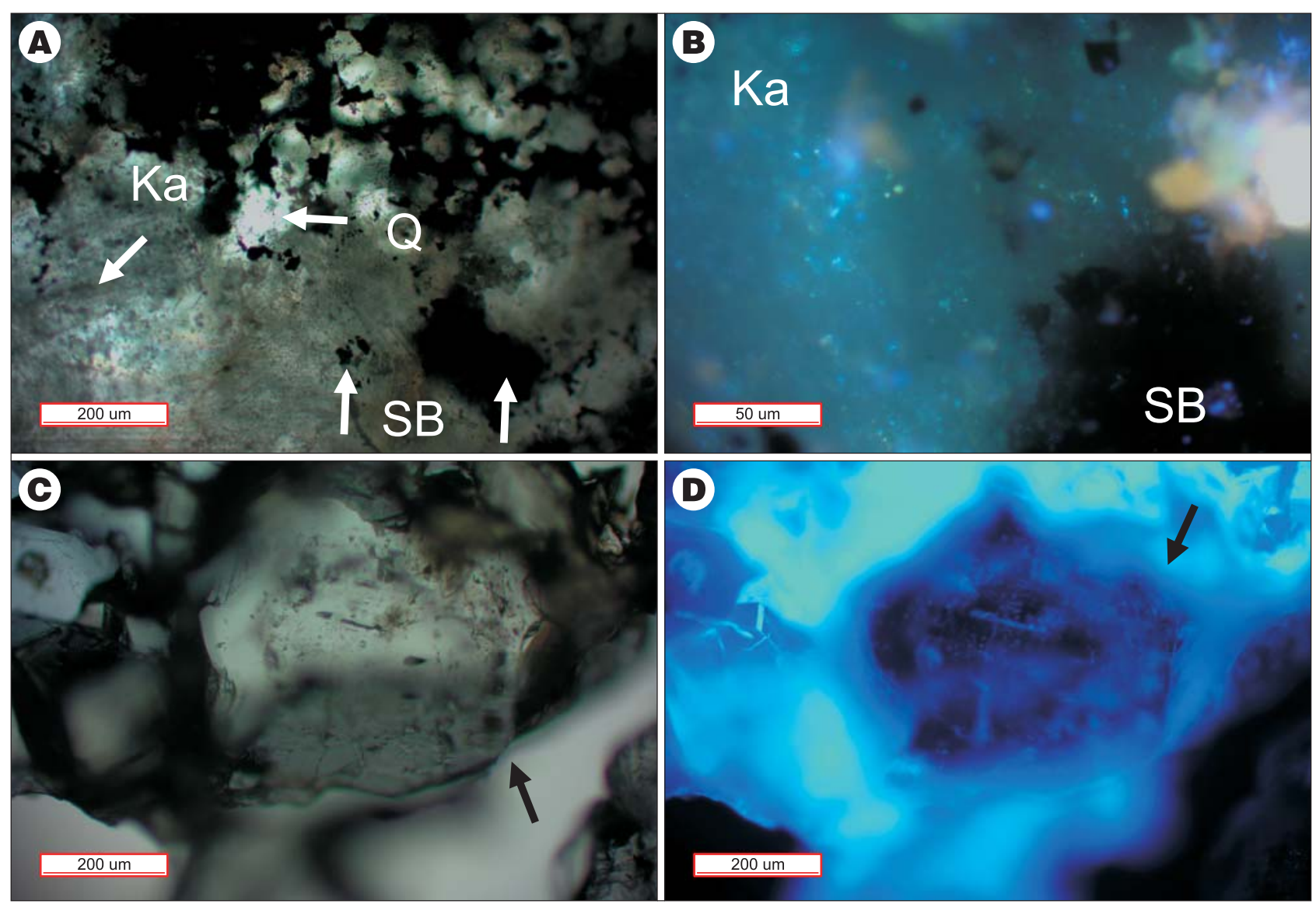

Ryc. 1. Inkluzje fluidalne i stałe w minerałach wypełnienia kawerny w rejonie Rabego (Karpaty). A - współwystępowanie węglanów (Ka), kwarcu (Q) i substancji bitumicznej (SB), B - fluorescencja inkluzji wtórnych w węglanie, C - inkluzje fluidalne w kwarcu, światło przechodzące, 1 polaryzator, $\mathbf{D}$ - brak świecenia inkluzji w kwarcu, obraz ziarna z ryc. 1C w świetle odbitym, nadfiolet. Czarne strzałki pokazują ten sam kryształ

Fig. 1. Fluid and solid inclusions in minerals filling a cavern in the Rabe vicinity (Carpathians). $\mathbf{A}$ - cooccurrence of carbonates (Ka), quartz (Q) and organic matter (SB), B - fluorescence of some inclusions in the carbonate, $\mathbf{C}$ - fluid inclusions in quartz, polarized light, D - no fluorescence of inclusions in quartz, image of the grain from Fig. 1C in reflected light, UV. Black arrows point the same crystal

nerału. Badania potwierdziły wodny charakter AQFI, ale nie wskazały na obecność gazów ani innych składników.

W kwarcu natomiast, jak pokazują widma Ramana, wszystkie badane inkluzje fluidalne posiadają rozpuszczony metan, któremu towarzyszy zmienna zawartość słabo uwęglonej substancji organicznej (ryc. 2). Potwierdza to wynik przeprowadzonych badań mikrotermometrycznych, gdzie w niewielkich, ciemnych, jednofazowych wrostkach zdiagnozowano metan. Analiza 33 widm substancji organicznej wykonana metodą Kouketsu i in. (2014) wykazała temperaturę przeobrażeń termicznych w zakresie $159^{\circ} \mathrm{C}$ $196^{\circ} \mathrm{C}$ i bardzo małą zmienność (tab. 2 - wartości średnie). Wyniki te są zbieżne w swym zakresie z oznaczeniami temperatury homogenizacji zarówno dla dwufazowych inkluzji fluidalnych w kwarcu $\left(178,9-186,0^{\circ} \mathrm{C}\right)$, jak i w węglanie. Temperatury homogenizacji inkluzji dla węglanu mieszczą się w zakresie od 155,7 do $180^{\circ} \mathrm{C}$. Trzeba tu jednakże podkreślić, że inkluzje fluidalne są często porozciaggane, nieregularne, a wysoka dwójłomność w węglanie stanowi duże utrudnienie w obserwacjach procesów zachodzących we wnętrzu wrostków podczas procesów podgrzewania i zamrażania. Potwierdzenie rozpuszczonego metanu w inkluzjach wodnych predystynuje do szacowania warunków PT (ciśnienia i temperatury) wspólnego uwięzienia solanki i metanu w kwarcu. Warunki te określono dla przecinających się izochor na $210^{\circ} \mathrm{C}$ i 500 barów.

\section{WNIOSKI}

W asocjacji kwarc-węglan-bituminy występującej w rejonie Rabego (melanż tektoniczny) w wypełnieniach przestrzeni w skałach w oparciu o przeprowadzone badania inkluzji fluidalnych i wrostków stałych można stwierdzić obecność następujących fluidów:

- solanki o składzie i stężeniu zróżnicowanym w zależności od minerału (kwarc, węglan), niekiedy z dwutlenkiem węgla;

- metanu $\left(\mathrm{CH}_{4}\right)$ o gęstości 0,172 g/ $\mathrm{cm}^{3}$ w kwarcu, zdiagnozowanego bezpośrednio w inkluzjach i na widmie Ramana;

- niewielkich ilości wyższych węglowodorów (ropa naftowa o dużej dojrzałości) o charakterze wtórnych inkluzji w węglanach.

Substancja organiczna nagromadzona w postaci wrostków i skupień wskazuje temperaturę przeobrażeń termicznych skały pomiędzy 159 a $196^{\circ} \mathrm{C}$.

Temperatury homogenizacji inkluzji dwufazowych w węglanie i kwarcu mieszczą się w zakresie $155,7-180^{\circ} \mathrm{C}$ i $178,9-186,0^{\circ} \mathrm{C}$.

Wspólne uwięzienie solanki i metanu w rejonie Rabego mogło nastąpić w temperaturze $210^{\circ} \mathrm{C}$ i ciśnieniu 500 barów.

Autorzy dziękują recenzentom M. Dumańskiej-Słowik i Ł. Karwowskiemu za cenne uwagi i wskazówki, których zastosowanie wzbogaciło treść pracy. Artykuł został opracowany w ramach zadania Wspótpraca krajowa w zakresie geologii i promocja 


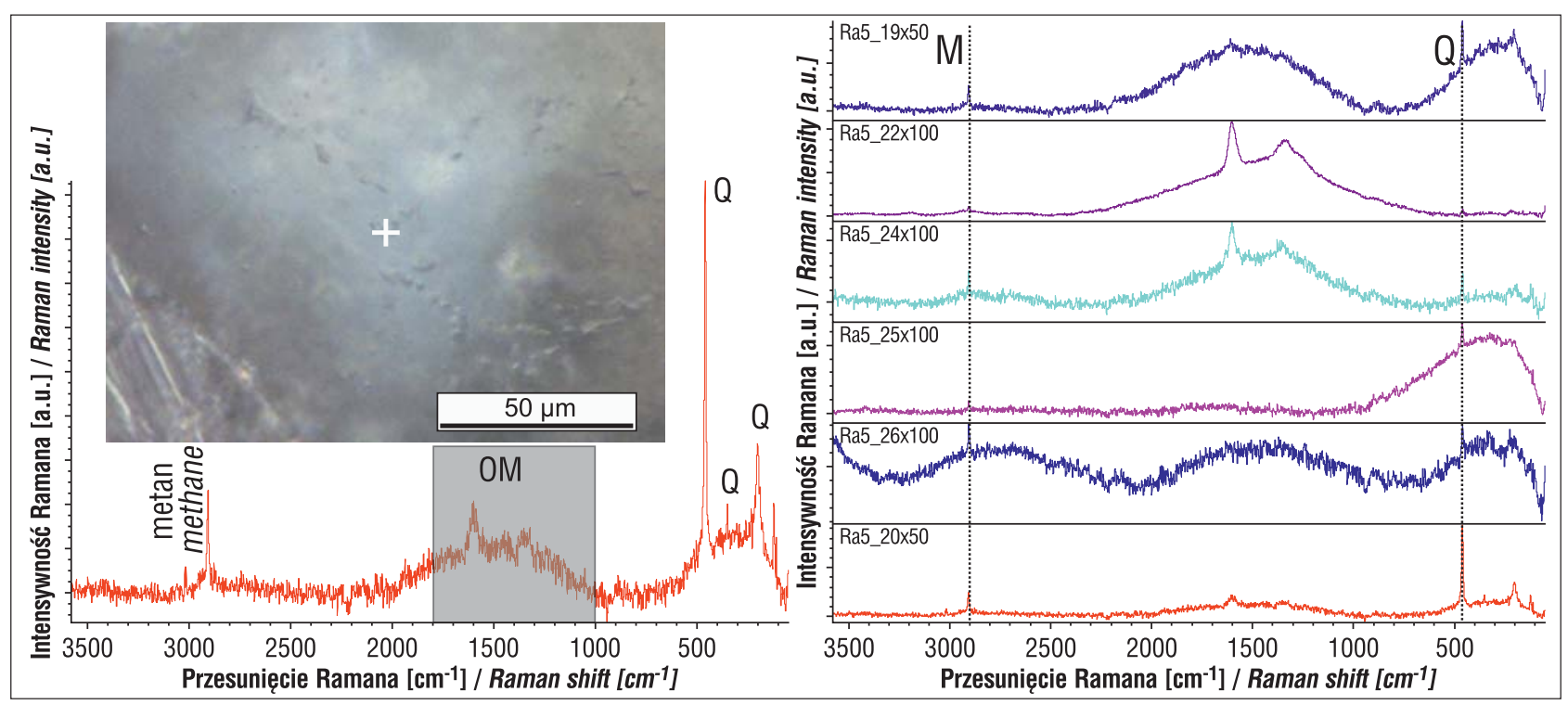

Ryc. 2. Wyniki badań widma Ramana w próbce Ra5. A - ziarno kwarcu i widmo pokazujące piki dla metanu, substancji bitumicznej (OM) i kwarcu (Q). B - zestawienie widm ramanowskich inkluzji fluidalnych w kwarcu (Q - główne pasmo kwarcu) zawierających metan (M-pasmo metanu)

Fig. 2. Results of the Raman analysis in the Ra5 sample. A - quartz crystal and its spectrum showing peaks for methane, organic matter $(\mathrm{OM})$ and quartz $(\mathrm{Q})$. B - compilation of Raman spectra for methane-bearing FI (M - methane band) in quartz (Q - main quartz band)

Tab. 2. Parametry statystyczne dla 33 widm ramanowskich materii organicznej i temperatury jej przeobrażeń obliczone wg procedury Kouketsu i in. (2014)

Table 2. Statistical parameters for 33 Raman spectra of organic matter, and temperatures of its alteration calculated acc. to the procedure of Kouketsu et al. (2014)

\begin{tabular}{|c|c|c|c|c|c|}
\hline \multirow{2}{*}{$\begin{array}{l}\text { Parametry statystyczne } \\
\text { Statistical parameters }\end{array}$} & \multicolumn{4}{|c|}{$\begin{array}{c}\text { Szerokości polówkowe pików (FWHH) } \\
\text { Half width of bands }\end{array}$} & \multirow{2}{*}{$\begin{array}{c}\text { Temperatura } \\
\text { Temperature } \\
{\left[{ }^{\circ} \mathrm{C}\right]}\end{array}$} \\
\hline & D4 $\left(1250 \mathrm{~cm}^{-1}\right)$ & D1 $\left(1350 \mathrm{~cm}^{-1}\right)$ & D3 $\left(1500 \mathrm{~cm}^{-1}\right)$ & GL $\left(1580 \mathrm{~cm}^{-1}\right)$ & \\
\hline Średnia / Average & 110,51 & 139,66 & 171,81 & 48,63 & 177,7 \\
\hline Mediana / Median & 112,61 & 140,75 & 169,19 & 48,58 & 175,4 \\
\hline $\begin{array}{l}\text { Odchylenie standardowe } \\
\text { Standard deviation }\end{array}$ & 7,96 & 3,98 & 19,67 & 1,05 & 8,55 \\
\hline $\begin{array}{l}\text { Współczynnik zmienności [\%] } \\
\text { Coefficient of variation }\end{array}$ & 7,20 & 2,85 & 11,45 & 2,17 & 4,81 \\
\hline
\end{tabular}

działań państwowej slużby geologicznej w latach 2021-2023 i sfinansowany ze środków Narodowego Funduszu Ochrony Środowiska i Gospodarki Wodnej.

\section{LITERATURA}

BAKKER R.J., BROWN P.E. 2003 - Computer modeling in fluid inclusion research. [W:] Samson I., Anderson A., Marshall D. (red.), Fluid inclusions: analysis and interpretation. Short Course. Mineral. Assoc. Can., 32: $185-203$.

BEYSSAC O , GOFFÉ B., CHOPIN C., ROUZAUD J.N. 2003 - Raman spectra of carbonaceous material in metasediments: a new geothermometer. J. Metamorph. Geol., 20: 859-871.

BROWN P.E. 1989 -Flincor: A microcomputer program for the reduction and investigation of fluid inclusion data. Am. Mineral., 74: 1390-1393.

BURKE E.A.J. 2001 - Raman microspectrometry of fluid inclusions. Lithos, 55: 139-158.

DUTKIEWICZ A., RIDLEY J., BUICK R. 2003 - Oil-bearing $\mathrm{CO}_{2}-\mathrm{CH}_{4}-\mathrm{H}_{2} \mathrm{O}$ fluid inclusions: oil survival since the Palaeoproterozoic after high temperature entrapment. Chem. Geol., 194: 51-79.

FREZZOTTI M.L., TECCE F., CASAGLI A. 2012 - Raman spectroscopy for fluid inclusion analyses. J. Geochem. Explor., 112: 1-20.

GOLDSTEIN R.H. 2001 - Fluid inclusions in sedimentary and diagenetic systems. Lithos, 55: 159-193.

GOLDSTEIN R.H., REYNOLDS T.J. 1994 - Systematics of fluid inclusions in diagenetic minerals. SEPM Short Course, 31. Tulsa. DUDOK I.V., JARMOŁOWICZ-SZULC K. 2000 - Hydrocarbon inclusions in vein quartz (the „Marmarosh diamonds") from the Krosno and Dukla zones of the Ukrainian Carpathians. Geol. Quart., 44: 415-423.
JANKOWSKI L., JARMOŁOWICZ-SZULC K. 2009 - Particular tectonic zones (the mélange zones) as potential and significant paths for fluid migration and mineral formation. Mineralog. Rev., 59 (2): 42-55. JARMOŁOWICZ-SZULC K. 1999 - Systematyka inkluzji fluidalnych w wypełnieniach przestrzeni porowej skał osadowych paleozoiku Niżu Polskiego. Prz. Geol., 47 (6): 542-546.

JARMOŁOWICZ-SZULC K., KARWOWSKI Ł., MARYNOWSKI L. 2012 - Fluid circulation and formation of minerals and bitumen in the sedimentary rocks of the Outer Carpathians - based on studies on the quartz-calcite-organic matter association. Marin. Petrol. Geol., 32: 138-158. KOUKETSU Y., MIZUKAMI T., MORI H., ENDO S., AOYA M., HARA H., NAKAMURA D., WALLIS S. 2014 - A new approach to develop the Raman carbonaceous material geothermometer for low-grade metamorphism using peak width. Island Arc., 23: 33-50.

PING H., CHEN H., GEORGE S.C. 2020 - Quantitatively predicting the thermal maturity of paleo-oil trapped in fluid inclusions based on fluorescent and molecular geochemical data of oil inclusions in the Dongying Depression, Bohai Bay Basin. AAPG Bulletin, 104: 1751-1791.

ROEDDER E. 1984 - Fluid inclusions. Reviews in Mineralogy. Mineral. Soc. Am., 12.

SAMSON I., ANDERSON A., MARSHALL D. (red.) 2003 - Fluid inclusions: analysis and interpretation. Short Course. Mineral. Ass. Can., 32: $185-203$.

TOBOŁA T. 2018 - Raman spectroscopy of organic, solid and fluid inclusions in the Oldest Halite of LGOM area (SW Poland). Spectrochim. Acta A Mol. Biomol. Spectrosc., 189: 381-392.

TOBOŁA T., BOTOR D. 2020 - Raman spectroscopy of organic matter and rare minerals in the Kłodawa Salt Dome (Central Poland) cap-rock and Triassic cover - Indicators of hydrothermal solution migration. Spectrochim. Acta A Mol. Biomol. Spectrosc., 231, Art. 118121: 1-16.

Praca wpłynęła do redakcji 15.03.2021 r.

Akceptowano do druku 23.04.2021 r. 